\title{
Evaluation of Breast Cancer Resistance Protein Function in Hepatobiliary and Renal Excretion Using PET with ${ }^{11} \mathrm{C}-\mathrm{SC}-62807$
}

\author{
Tadayuki Takashima ${ }^{1}$, Chunyong $\mathrm{Wu}^{2}$, Misato Takashima-Hirano ${ }^{1}$, Yumiko Katayama ${ }^{1}$, Yasuhiro Wada ${ }^{1}$, \\ Masaaki Suzuki ${ }^{1}$, Hiroyuki Kusuhara ${ }^{2}$, Yuichi Sugiyama ${ }^{3}$, and Yasuyoshi Watanabe ${ }^{1}$ \\ ${ }^{I}$ RIKEN Center for Molecular Imaging Science, Kobe, Japan; ${ }^{2}$ Laboratory of Molecular Pharmacokinetics, Graduate School of \\ Pharmaceutical Sciences, The University of Tokyo, Tokyo, Japan; and ${ }^{3}$ Sugiyama Laboratory, RIKEN Innovation Center, RIKEN \\ Research Cluster for Innovation, Yokohama Bio Industry Center, Yokohama, Japan
}

\begin{abstract}
A quantitative PET imaging method was used to assess the in vivo kinetics of hepatobiliary and renal excretion of the breast cancer resistance protein (Bcrp) substrate ${ }^{11} \mathrm{C}-\mathrm{SC}-62807$ in mice. Methods: Serial abdominal PET scans were collected in wild-type and Bcrp knockout $\left(\mathrm{Bcrp}^{-1-}\right)$ mice after intravenous injection of ${ }^{11} \mathrm{C}-\mathrm{SC}-62807$. Venous blood samples and PET images were obtained at frequent intervals up to $30 \mathrm{~min}$ after radiotracer administration. Dynamic PET data were analyzed to determine the canalicular and brush-border efflux clearances in the liver and kidney $\left(\mathrm{CL}_{\text {int, bile,liver }}\right.$ and $\mathrm{CL}_{\text {int, urine, kidney, re- }}$ spectively). Results: SC-62807 is an in vitro substrate of mouse Bcrp and human BCRP. Radioactivity associated with ${ }^{11} \mathrm{C}-\mathrm{SC}-62807$ was predominantly found in the blood, liver, bile, and urine $30 \mathrm{~min}$ after administration. Both biliary and urinary excretion of radioactivity was markedly lower in $\mathrm{Bcrp}^{-/-}$mice than in wild-type mice, suggesting greater systemic exposure in $\mathrm{Bcrp}^{-1-}$ mice. Both the $\mathrm{CL}_{\text {int,bile,liver }}$ and the $\mathrm{CL}_{\text {int,urine,kidney }}$ were significantly lower in $\mathrm{Bcrp} \mathrm{c}^{-/}$mice $(74 \% \pm 10 \%$ and $99 \% \pm 1 \%$ lower than controls, respectively). We also found that ${ }^{11} \mathrm{C}-\mathrm{SC}-$ 62807 is a substrate of the organic anion-transporting polypeptides OATP1B1 and OATP1B3 in vitro. Conclusion: The present study demonstrated that Bcrp plays a significant role in the efflux of ${ }^{11} \mathrm{C}-\mathrm{SC}-62807$ in mouse liver and kidney. We also demonstrated the feasibility of PET using ${ }^{11} \mathrm{C}-\mathrm{SC}-62807$ to study the activity of BCRP in humans.
\end{abstract}

Key Words: breast cancer resistance protein; organic aniontransporting polypeptide; positron emission tomography; hepatobiliary transport; renal excretion

J Nucl Med 2013; 54:267-276

DOI: 10.2967/jnumed.112.110254

\footnotetext{
Received Jun. 20, 2012; revision accepted Aug. 23, 2012.

For correspondence or reprints contact: Tadayuki Takashima, Molecular Probe Dynamics Laboratory, RIKEN Center for Molecular Imaging Science, 6-7-3 Minatojima-minamimachi, Chuo-ku, Kobe, Hyogo 650-0047, Japan. E-mail: ttakashima@riken.jp

Published online Jan. 3, 2013

COPYRIGHT @ 2013 by the Society of Nuclear Medicine and Molecular Imaging, Inc.
}

D rug transporters play an important role in drug disposition and may influence therapeutic efficacy or development of adverse drug reactions (1-3). The breast cancer resistance protein (Bcrp, rodents; BCRP/ABCG2, humans) is a member of the adenosine triphosphate (ATP)-binding cassette transporter G family and mediates the efflux transport of endobiotics and xenobiotics coupled with ATP hydrolysis (4-6). BCRP is expressed in various normal tissues, including liver, kidney, brain, placenta, and intestine, where it is expressed on the brush-border membranes of epithelial cells (7). Cumulative in vivo studies, particularly involving Bcrp knockout $\left(\mathrm{Bcrp}^{-/-}\right)$mice, have demonstrated the important role BCRP plays in drug disposition, limiting oral absorption and penetration into the brain and testis (8), and mediating biliary and urinary excretion of xenobiotics such as pitavastatin and methotrexate (1,911). Pharmacogenomic studies focusing on a single nucleotide polymorphism frequently observed in Asians $(421 \mathrm{C}>\mathrm{A})$ elucidated the importance of BCRP in systemic exposure to orally administered sulfasalazine and rosuvastatin $(12,13)$. Because of the lack of a suitable probe, the role of BCRP in the elimination of BCRP substrates from the systemic circulation and their distribution in the brain has not been investigated. Furthermore, because BCRP eliminates uric acid, mutations and single nucleotide polymorphisms in this protein make it a risk factor for gout and are thus drawing increasing research interest (14). The many important roles played by BCRP make it a subject of major clinical interest.

PET is a powerful noninvasive molecular imaging technique that provides high sensitivity and good spatiotemporal resolution, enabling determination of the tissue concentration of drugs labeled with a positron-emitting radionuclide (15-17). The usefulness of transporter probes for molecular imaging has been demonstrated through in vivo phenotypic measurements of altered hepatobiliary transport of organic anion-transporting polypeptide (Oatp, rodents; OATP, humans) and multidrug resistance-associated protein 2 (Mrp2, rodents; MRP2, humans) in preclinical and 
clinical tests using ${ }^{99 \mathrm{~m}} \mathrm{Tc}-\mathrm{mebrofenin}(18)$ and $15 R-{ }^{11} \mathrm{C}$ TIC-Me $(19,20)$. Recently, functional PET probes for Bcrp and $\mathrm{P}$-glycoprotein, such as ${ }^{11} \mathrm{C}$-elacridar and ${ }^{11} \mathrm{C}$-gefitinib, have been described for use in the noninvasive in vivo evaluation of these proteins at the blood-brain barrier (BBB) $(21,22)$. However, because the major elimination pathway of these probes is metabolism, they cannot be used to evaluate efflux activity in the liver and kidney.

SC-62807 is the major metabolite of celecoxib (a selective cyclooxygenase- 2 inhibitor) and is produced by CYP2C9 (23). Because SC-62807 contains a carboxylate group and does not undergo further metabolism, we hypothesized that SC-62807 would be a good probe for certain efflux transporters in the liver, and we synthesized ${ }^{11} \mathrm{C}-\mathrm{SC}$ 62807 for this purpose (Fig. 1). We previously demonstrated that in rats ${ }^{11} \mathrm{C}-\mathrm{SC}-62807$ is rapidly excreted into the bile without further metabolism (24). In this study, we elucidated the predominant role of Bcrp in the efflux of SC62807 into the bile and urine in mice and demonstrate the feasibility of using PET to evaluate BCRP activity in humans.

\section{MATERIALS AND METHODS}

Celecoxib carboxylic acid (SC-62807) was purchased from Toronto Research Chemicals Inc. ${ }^{11} \mathrm{C}-\mathrm{SC}-62807$ was synthesized according to previously reported procedures (24). The chemical purity of ${ }^{11} \mathrm{C}-\mathrm{SC}-62807$ was determined by measuring the ultraviolet absorbance at $254 \mathrm{~nm}$. The radiochemical purity was greater than $98 \%$, and the specific radioactivity was $14 \pm 10 \mathrm{GBq} / \mu \mathrm{mol}$ at the time of injection. All chemicals and solvents used for labeling synthesis were analytic grade.

\section{Animals}

Male wild-type FVB and $B c r p^{-1}$ mice were purchased from Taconic Inc. (age, 6-12 wk, weight, 22-30 g). Mice were maintained in a temperature- and light-controlled environment with ad libitum access to standard food and tap water. All experimental protocols were approved by the Ethics Committee on Animal Care and Use of the Center for Molecular Imaging Science at RIKEN and were performed in accordance with the Guide for the Care and Use of Laboratory Animals (25).

\section{Determination of ATP-Dependent Uptake of SC-62807 by Transporter-Expressing Membrane Vesicles}

Membrane vesicles were prepared as described previously from HEK293 cells infected with adenoviruses expressing mouse Bcrp (mBcrp), human BCRP (hBCRP), and green fluorescent protein

FIGURE 1. Chemical structure of ${ }^{11} \mathrm{C}-\mathrm{SC}-62807$.
(GFP) (control) (26) and with recombinant adenoviruses containing human MRP2 and tetracycline-responsive transcriptional activator (27). A rapid filtration technique was used to assess ATP-dependent uptake (26). Samples were quantified using liquid chromatographytandem mass spectrometry. The level of ATP-dependent uptake was calculated by subtracting the uptake into vesicles in the presence of adenosine monophosphate (AMP) from that in the presence of ATP. Kinetic parameters were calculated using the Michaelis-Menten equation:

$$
v=\frac{V_{\max } \times S}{K_{\mathrm{m}}+S}
$$

where $v$ represents the uptake velocity of the substrate, $S$ represents the substrate concentration in the medium, $K_{\mathrm{m}}$ represents the Michaelis constant, and $V_{\max }$ represents the maximum uptake velocity. The nonlinear least-squares method was used for fitting (Damping Gauss-Newton method algorithm) with the MULTI program (28).

\section{PET Studies}

All PET scans were obtained using a microPET Focus 220 scanner (Siemens) designed for laboratory animals. Mice were anesthetized and maintained with a mixture of $1.5 \%$ isoflurane and oxygen and then placed on the PET scanner gantry. An emission scan was performed after intravenous bolus injection of ${ }^{11} \mathrm{C}-\mathrm{SC}$ $62807(158 \pm 32 \mathrm{MBq} / \mathrm{kg})$ via a catheter inserted into the tail. The bolus injections contained $0.23 \pm 0.19 \mu \mathrm{g}$ of SC-62807 per animal. An emission scan was obtained in 3-dimensional list mode for $30 \mathrm{~min}$ and sorted into 26 dynamic sinograms according to the following sequence: $12 \times 5,3 \times 20,3 \times 60,5 \times 120$, and $3 \times 300 \mathrm{~s}$. Blood was sampled via the tail vein at the following time points: $2,5,15,30$, and 60 min after radiotracer administration. In addition, the biodistribution in a separate group of mice was also determined. After blood and urine sampling, blood flow was terminated by exsanguination via aortic puncture, and the liver and kidneys were quickly removed, weighed, and assayed for regional radioactivity using a 1470 Wizard automatic $\gamma$-counter (PerkinElmer). The radioactivity measured in each sample was decay-corrected to the injection time and expressed as percentage dose per tissue or percentage dose per milliliter of blood, normalized to the injected radioactivity.

\section{Radiometabolite Analysis}

Radiometabolites in the blood, urine, liver, and bile of a separate group of mice $(n=2)$ were analyzed using radiometric high-performance liquid chromatography. Blood and urine were collected $15 \mathrm{~min}$ after the mice received an intravenous injection of ${ }^{11} \mathrm{C}-\mathrm{SC}$ $62807(\sim 211 \pm 21 \mathrm{MBq} / \mathrm{kg})$, and bile was sampled from the gallbladder $30 \mathrm{~min}$ after injection. To sample liver tissue, blood flow was terminated $15 \mathrm{~min}$ after administration, and the liver was quickly removed and homogenized. Sample preparation and chromatographic separation were performed as described previously (24).

\section{Analysis of PET Data}

PET images were reconstructed using microPET Manager 2.4.1.1 (Siemens) by standard 2-dimensional filtered backprojection using a ramp filter with a cutoff at the Nyquist frequency. Regions of interest representing the liver and the intestines were delineated using PMOD software (version 3.0; PMOD Technologies Ltd.), as described previously (19). In this PET analysis, the sum of the radioactivity in the gallbladder and intestine corresponds 
to the radioactivity in the bile secreted to these tissues because a conventional biodistribution study revealed that the bile radioactivity sampled from rats with bile duct cannulas is comparable to that in the intestine as determined by PET image analysis (24). A time profile of the radioactivity in each tissue was constructed by normalizing decay-corrected time-radioactivity measurements to the injected dose (percentage dose) of ${ }^{11} \mathrm{C}-\mathrm{SC}-62807$.

The biliary secretion clearance $\left(\mathrm{CL}_{\mathrm{bile}, \text { blood,0-30 } \mathrm{min}}\right)$ and renal clearance $\left(\mathrm{CL}_{\text {renal,blood,0-30 } \mathrm{min}}\right)$ with respect to the blood radioactivity concentration were calculated using the following equations:

$$
\mathrm{CL}_{\text {bile,blood, } 0-30 \mathrm{~min}}=\mathrm{X}_{\mathrm{bil}, 0-30 \mathrm{~min}} / \mathrm{AUC}_{\mathrm{blood}, 0-30 \mathrm{~min}}
$$

and

$$
\mathrm{CL}_{\text {urine,blood }, 0-30 \min }=\mathrm{X}_{\text {urine }, 0-30 \mathrm{~min}} / \mathrm{AUC}_{\text {blood }, 0-30 \mathrm{~min}},
$$

where $\mathrm{X}$ represents the amount of radioactivity secreted into the bile or urine between 0 and $30 \mathrm{~min}$, and $\mathrm{AUC}_{\text {blood,0-30 min }}$ represents the area under the blood radioactivity concentration-time curve for the time period 0-30 min.

The apparent tissue-to-blood area under the curve (AUC) ratio ( $\mathrm{K}_{\mathrm{p} \text {,liver,AUC }}$ or $\mathrm{K}_{\mathrm{p}, \mathrm{kidney}, \mathrm{AUC}}$ ) was calculated using the following equation:

$$
\mathrm{K}_{\mathrm{p}, \mathrm{tissue}, \mathrm{AUC}}=\mathrm{AUC}_{\mathrm{tissue}, 0-30 \mathrm{~min}} / \mathrm{AUC}_{\mathrm{blood}, 0-30 \mathrm{~min}}, \quad \text { Eq. } 4
$$

where $\mathrm{AUC}_{\text {tissue, } 0-30 \text { min }}$ represents the area under the tissue radioactivity concentration-time curve for the time period 0-30 min.

Canalicular efflux clearance $\left(\mathrm{CL}_{\text {int,bile,liver }}\right)$ was estimated by integration plot analysis using noninvasive measurements of radioactivity in the liver and bile encompassing about the first 27.5 min after ${ }^{11} \mathrm{C}-\mathrm{SC}-62807$ administration, during which the plot shows linear regression. Kidney brush-border efflux clearance with respect to the kidney concentration $\left(\mathrm{CL}_{\text {int,urine,kidney }}\right)$ was estimated by integration plot analysis using the radioactivity in the kidney and urine encompassing about the first 6 min after ${ }^{11} \mathrm{C}-\mathrm{SC}-62807$ administration for wild-type mice and the first 27.5 min after administration for $\mathrm{Bcrp}^{-/-}$mice. Biliary efflux and kidney brush-border efflux clearances were calculated using the following equations:

$$
\mathrm{X}_{\mathrm{t}, \text { bile }}=\mathrm{CL}_{\text {int,bile,liver }} \times \mathrm{AUC}_{0-\mathrm{t}, \text { liver }}+\mathrm{X}_{\mathrm{E} \text {,bile }}
$$

and

$$
\mathrm{X}_{\mathrm{t}, \text { urine }}=\mathrm{CL}_{\text {int, urine,kidney }} \times \mathrm{AUC}_{0-\mathrm{t}, \text { kidney }}+\mathrm{X}_{\mathrm{E} \text {,urine }},
$$

where $X_{t, b i l e}$ and $X_{t, \text { urine }}$ represent the amount of radioactivity excreted into the bile and urine, respectively, at time $t$ as determined by PET image analysis. The areas under the hepatic and renal concentration-time curves from time 0 to time $t$ are represented by $\mathrm{AUC}_{0-\mathrm{t}, \text { liver }}$ and $\mathrm{AUC}_{0-\mathrm{t}, \mathrm{kidney}}$, respectively. The $\mathrm{CL}_{\text {int,bile,liver }}$ and $\mathrm{CL}_{\text {int, urine,kidney }}$ can be obtained from the slopes of plots of $\mathrm{X}_{\mathrm{t} \text {,bile }}$ versus $\mathrm{AUC}_{0-\mathrm{t} \text {,liver }}$ and $\mathrm{X}_{\mathrm{t}, \text { urine }}$ versus $\mathrm{AUC}_{0-\mathrm{t} \text {,kidney, }}$ respectively. Values for $\mathrm{X}_{\mathrm{E} \text {,urine }}$ and $\mathrm{X}_{\mathrm{E} \text {,bile }}$ were determined from the $y$-intercept of the respective integration plots, representing the initial distribution in these regions of interest (tissues) at time 0 .

\section{Uptake by Transporter-Expressing HEK293 Cells}

OATP1B1- and OATP1B3-expressing HEK293 cells were established previously (29). The transport study was performed as described previously (29). Briefly, cells were seeded onto 12-well plates coated with poly-L-lysine and poly-L-ornithine. After $2 \mathrm{~d}$, the culture medium was replaced with medium supplemented with $5 \mathrm{mM}$ sodium butyrate, and cells were incubated for $24 \mathrm{~h}$ before the transport study to induce transporter expression. Cells were then washed and preincubated with Krebs-Henseleit buffer. Uptake was initiated by adding buffer containing radiolabeled compounds or unlabeled SC-62807 and terminated at the designated time by adding ice-cold buffer after removal of the incubation buffer. To assess uptake of radiolabeled compounds, cells were solubilized with $0.2 \mathrm{~N} \mathrm{NaOH}$ and kept overnight at $4^{\circ} \mathrm{C}$. After neutralization with $\mathrm{HCl}$, aliquots were transferred to scintillation vials and radioactivity associated with the cells and incubation buffer was measured using a liquid scintillation counter (LS6000SE; Beckman Coulter) after the addition of scintillation cocktail (Clear-sol I; Nacalai Tesque). To assess uptake of SC62807 , cells were solubilized in $\mathrm{H}_{2} \mathrm{O}$ by sonication on ice. Aliquots of the cell lysate were extracted with ethyl acetate, and sulfasalazine was used as the internal standard. After centrifugation, the supernatants were evaporated, reconstituted with $10 \mathrm{mM}$ ammonium acetate/methanol (40:60, v/v), and quantitatively analyzed using liquid chromatography-tandem mass spectrometry. The remaining cell lysate was used to determine the protein concentration using the Lowry method with bovine serum albumin as a standard.

\section{Estimating Contribution of OATP1B1 and OATP1B3 to SC-62807 Uptake by Human Hepatocytes}

The contribution of OATP1B1 and OATP1B3 to SC-62807 uptake by human hepatocytes was estimated using relative activity factor analysis, as described in detail elsewhere $(28,29)$. Briefly, relative activity factors for OATP1B1 and OATP1B3 $\left(\mathrm{R}_{1 \mathrm{~B} 1}\right.$ or $\mathrm{R}_{1 \mathrm{~B} 3}$ ) were calculated as the uptake clearance in human hepatocytes $\left(\mathrm{CL}_{\text {hepatocyte,ref }}\right)$ divided by $\mathrm{CL}_{1 \mathrm{~B} 1 \text {, ref }}$ or $\mathrm{CL}_{1 \mathrm{~B} 3 \text {, ref }}$ using the reference compounds ${ }^{3} \mathrm{H}-\mathrm{E}_{1} \mathrm{~S}$ and ${ }^{3} \mathrm{H}-\mathrm{CCK}-8$ for OATP1B1 and OATP1B3, respectively:

$$
\begin{aligned}
& \mathrm{R}_{1 \mathrm{~B} 1}=\frac{\mathrm{CL}_{\text {hepatocyte,ref }}}{\mathrm{CL}_{1 \mathrm{~B} 1, \mathrm{ref}}}, \\
& \mathrm{R}_{1 \mathrm{~B} 3}=\frac{\mathrm{CL}_{\text {hepatocyte,ref }}}{\mathrm{CL}_{1 \mathrm{~B} 3, \mathrm{ref}}} .
\end{aligned}
$$

The uptake clearance of SC-62087 in hepatocytes ( $\left.\mathrm{CL}_{\text {hepatocytes,SC }}\right)$ was estimated as the product of the $R$ values $\left(R_{1 B 1}\right.$ and $\left.R_{1 B 3}\right)$ and uptake clearance of SC-62087 in OATP1B1- and OATP1B3expressing HEK293 cells (CL OATP1B1,SC $_{\text {and }} \mathrm{CL}_{\mathrm{OATP} 1 \mathrm{~B} 3, \mathrm{SC}}$ ) using the following equation:

$$
\mathrm{CL}_{\text {hepatocyte, } \mathrm{SC}}=\mathrm{R}_{1 \mathrm{~B} 1} \times \mathrm{CL}_{1 \mathrm{~B} 1, \mathrm{SC}}+\mathrm{R}_{1 \mathrm{~B} 3} \times \mathrm{CL}_{1 \mathrm{~B} 3, \mathrm{SC}} \text {. Eq. } 9
$$

The contributions of OATP1B1 and OATP1B3 are defined as the product of $\mathrm{R}_{1 \mathrm{~B} 1}$ and $\mathrm{CL}_{1 \mathrm{~B} 1, \mathrm{SC}}$ divided by $\mathrm{CL}_{\text {hepatocyte,SC }}$ and the product of $\mathrm{R}_{1 \mathrm{~B} 3}$ and $\mathrm{CL}_{1 \mathrm{~B} 3, \mathrm{SC}}$ divided by $\mathrm{CL}_{\text {hepatocyte,sC, }}$ respectively.

\section{Statistical Analysis}

Data are presented as the mean \pm SD for 3-4 determinations. The statistical significance of differences between groups was de- 
termined using the Student 2-tailed unpaired $t$ test. Statistical significance was set at a $P$ value of less than 0.05 .

\section{RESULTS}

ATP-Dependent Uptake of SC-62807 into mBcrp- or hBCRP-Expressing Membrane Vesicles

Uptake of SC-62807 by membrane vesicles expressing $\mathrm{mBcrp}$ or hBCRP was markedly stimulated in the presence of ATP but not in the presence of AMP or in vesicles prepared from control cells (Fig. 2A). Uptake of SC-62807 was saturable and followed Michaelis-Menten kinetics, with $K_{\mathrm{m}}$ and $V_{\max }$ values of $19.9 \pm 3.9 \mu \mathrm{M}$ and $435 \pm$ $50 \mathrm{pmol} / \mathrm{min} / \mathrm{mg}$ of protein, respectively, for mBcrp and $10.4 \pm 1.73 \mu \mathrm{M}$ and $2,263 \pm 204 \mathrm{pmol} / \mathrm{min} / \mathrm{mg}$ of protein, respectively, for hBCRP (Fig. 2B).

\section{Distribution of Radioactivity in Abdominal Region and Blood of Mice After Administration of ${ }^{11} \mathrm{C}-S C-62807$}

Radioactivity localized primarily in the liver and kidneys within 2 min of ${ }^{11} \mathrm{C}-\mathrm{SC}-62807$ administration in both wildtype and $\mathrm{Bcrp}^{-/-}$mice and subsequently moved to the intestine (derived from bile) or the urinary bladder (derived from urine) in wild-type mice by $30 \mathrm{~min}$ after administration (Fig. 3A). In contrast, translocation of radioactivity to the intestine and urinary bladder was markedly delayed in Bcrp $^{-/}$mice (Fig. 3B).

Mouse abdominal region tissue and blood radioactivity time profiles are shown in Figure 4. A maximum of $35 \% \pm$ $8 \%$ and $14 \% \pm 3 \%$ of the dose was distributed in the liver and kidney, respectively, of wild-type mice by 2 min after administration, after which the amount of radioactivity declined rapidly. In contrast, radioactivity in the liver and kidney of $\mathrm{Bcrp}^{-/-}$mice reached a maximum at 4 and 18 min, respectively, and then decreased gradually. Radio- activity in the bile (sum of gallbladder and intestine) and urine of wild-type mice increased until $30 \mathrm{~min}$, reaching $48 \% \pm 3 \%$ and $26 \% \pm 5 \%$ of the dose, respectively, whereas the level of radioactivity in the bile and the urine was much lower. A separate conventional biodistribution study revealed that in wild-type and $\mathrm{Bcrp}^{-/-}$mice, the radiotracer is distributed primarily in the liver $(34 \%$ and $44 \%$ of dose, respectively) and to a lesser degree in the kidneys (3\% and $16 \%$ of dose) and urine (7\% and $0.02 \%$ of dose) at $5 \mathrm{~min}$ after administration. At $30 \mathrm{~min}$, radioactivity in the liver, kidney, and urine of wild-type and $\mathrm{Bcrp}^{-1}$ - mice was $10 \%$ and $25 \%, 0.4 \%$ and $14 \%$, and $5 \%$ and $9 \%$ of the dose, respectively. These data were comparable to the PET data. Radioactivity in the blood decreased rapidly in wild-type mice but decreased only slightly and then remained constant in $\mathrm{Bcrp}^{-/-}$mice. The $\mathrm{AUC}_{\mathrm{blood}, 0-30 \mathrm{~min}}$ for $\mathrm{Bcrp}^{-/}$mice $(93 \% \pm 19 \%$ of the dose $\times \mathrm{min} / \mathrm{mL})$ was 2.2-fold higher than that for wild-type mice $(42 \% \pm 18 \%$ of the dose $\times \mathrm{min} / \mathrm{mL}$ ) (Table 1). The liver-to-blood AUC ratio ( $\mathrm{K}_{\mathrm{p}, \text { liver,AUC }}$ ) was lower in $\mathrm{Bcrp}^{-/-}$mice than in wild-type mice; however, the difference was not statistically significant. The kidney-to-blood AUC ratio $\left(\mathrm{K}_{\mathrm{p}, \text { kidney,AUC }}\right)$ was significantly higher in $\mathrm{Bcrp}^{-/}$mice than in wild-type mice $(P<0.01)$ (Fig. 4; Table 1). High-performance liquid chromatography analysis revealed that almost $100 \%$ of the radioactivity in the blood, liver, bile, and urine represented unchanged ${ }^{11} \mathrm{C}-\mathrm{SC}-62807$ (Fig. 5), indicating that in mice ${ }^{11} \mathrm{C}-\mathrm{SC}-62807$ is rapidly eliminated without further metabolism via hepatobiliary and renal excretion.

\section{Canalicular Efflux and Kidney Brush-Border Efflux Clearance of ${ }^{11} \mathrm{C}-\mathrm{SC}-62807$ in Mice}

Clearance of radioactivity via canalicular and kidney brush-border efflux $\left(\mathrm{CL}_{\text {int,bile,liver }}\right.$ and $\mathrm{CL}_{\text {int, urine,kidney, }}$
FIGURE 2. Time profiles of SC-62807 uptake by mBcrp, hBCRP, and control vesicles. Uptake of SC-62807 (2 $\mu \mathrm{M})$ into membrane vesicles was determined in presence of ATP (closed symbols) or AMP (open symbols). Uptake was terminated at designated time. (A) Squares and circles connected using solid and broken lines represent uptake by transporter (mBcrp or hBCRP) and membrane vesicles (control) expressing green fluorescent protein, respectively. (B) Uptake of various concentrations $(0.22,2.18,10.8,29.7,68.9,142$, and $498 \mu \mathrm{M}$ for mBcrp and $0.23,2.21,10.6$, $23.3,44.5,87.8$, and $287 \mu \mathrm{M}$ for hBCRP) of SC-62807 into transporter-expressing membrane vesicles for $1 \mathrm{~min}$. Velocity of ATP-dependent uptake by mBcrp- and hBCRP-expressing vesicles was fitted to Michaelis-Menten equation using nonlinear regression analysis, and solid line in (B) represents fitted curve. Each point represents mean $\pm \operatorname{SE}(n=3)$.

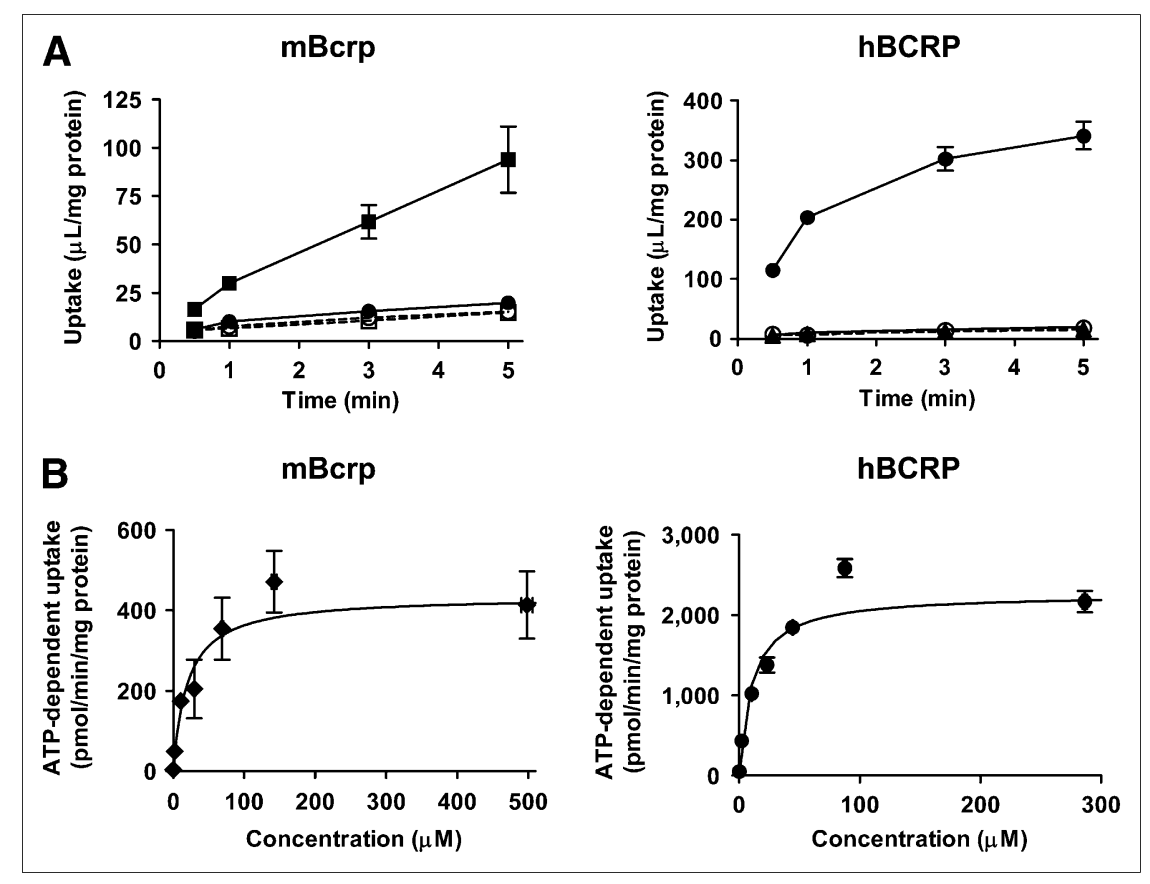




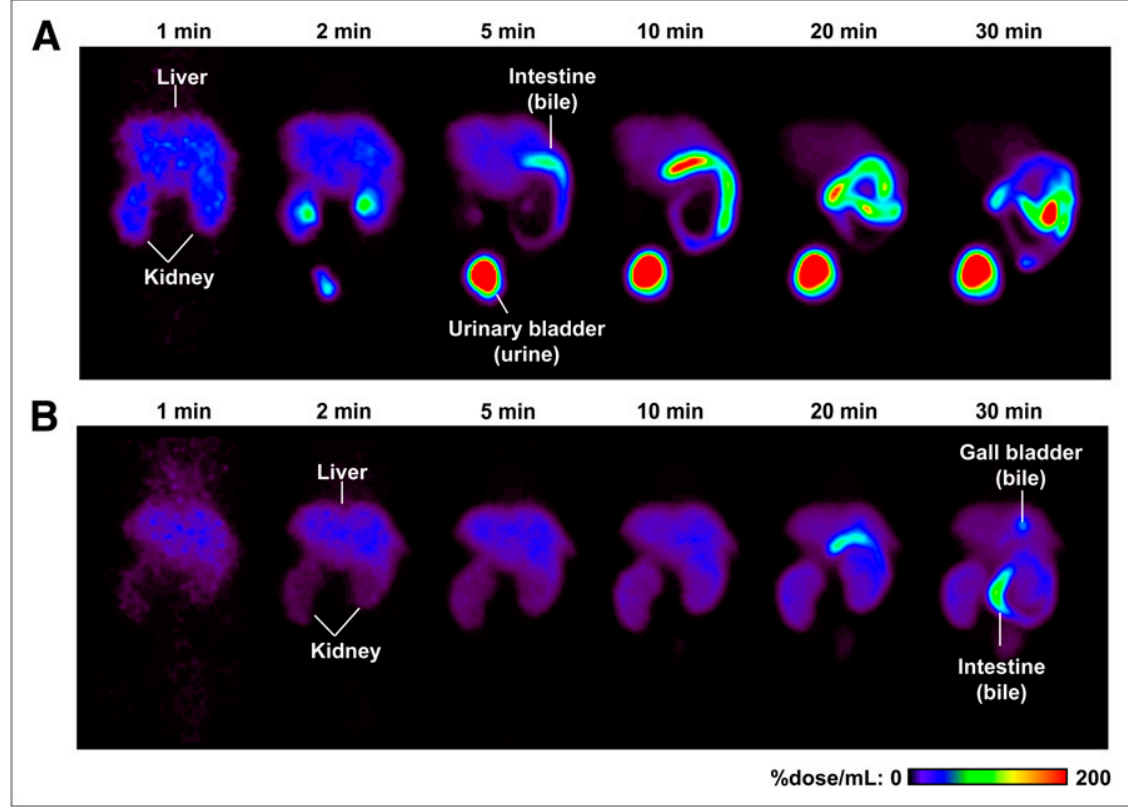

FIGURE 3. Color-coded PET images of abdominal region of wild-type and $\mathrm{Bcrp}^{-1-}$ mice after administration of ${ }^{11} \mathrm{C}-\mathrm{SC}-62807$. Coronal maximum-intensity-projection PET images of radioactivity in abdominal region of wildtype (A) and $\mathrm{Bcrp}^{-1-}$ (B) mice were captured at $1,2,5,10,20$, and 30 min after intravenous bolus administration of ${ }^{11} \mathrm{C}-\mathrm{SC}-62807$. respectively) was determined by integration plot analysis (Fig. 6). The integration plots used to determine $\mathrm{CL}_{\text {int,bile,liver }}$ for wild-type and $\mathrm{Bcrp}^{-1-}$ mice were linear $10 \mathrm{~min}$ after ${ }^{11} \mathrm{C}$ SC-62807 administration (Fig. 6A). The $\mathrm{CL}_{\text {int,bile,liver for }}$ $\mathrm{Bcrp}^{-\alpha}$ mice was significantly lower (by $74 \% \pm 10 \% ; P<$ $0.01)(1.2 \pm 0.1 \mathrm{~mL} / \mathrm{min} / \mathrm{kg})$ than that for wild-type mice (4.5 $\pm 0.8 \mathrm{~mL} / \mathrm{min} / \mathrm{kg}$ ) (Table 1). The integration plots used to determine $\mathrm{CL}_{\text {int,urine,kidney }}$ were linear within 6 min of ${ }^{11} \mathrm{C}-\mathrm{SC}$ 62807 administration for wild-type mice and within $30 \mathrm{~min}$ for $\mathrm{Bcrp}^{-\alpha}$ mice (Fig. 6B). The $\mathrm{CL}_{\text {int,urine,kidney }}$ for $\mathrm{Bcrp}^{-1-}$ mice $(0.12 \pm 0.07 \mathrm{~mL} / \mathrm{min} / \mathrm{kg})$ was significantly lower (by $99 \% \pm 1 \% ; P<0.001)$ than for wild-type mice $(13 \pm 2 \mathrm{~mL} /$ $\mathrm{min} / \mathrm{kg}$ ) (Table 1). The difference in $\mathrm{CL}_{\text {int,bile,liver between }}$ wild-type and $\mathrm{Bcrp}^{-/}$mice was smaller than the difference

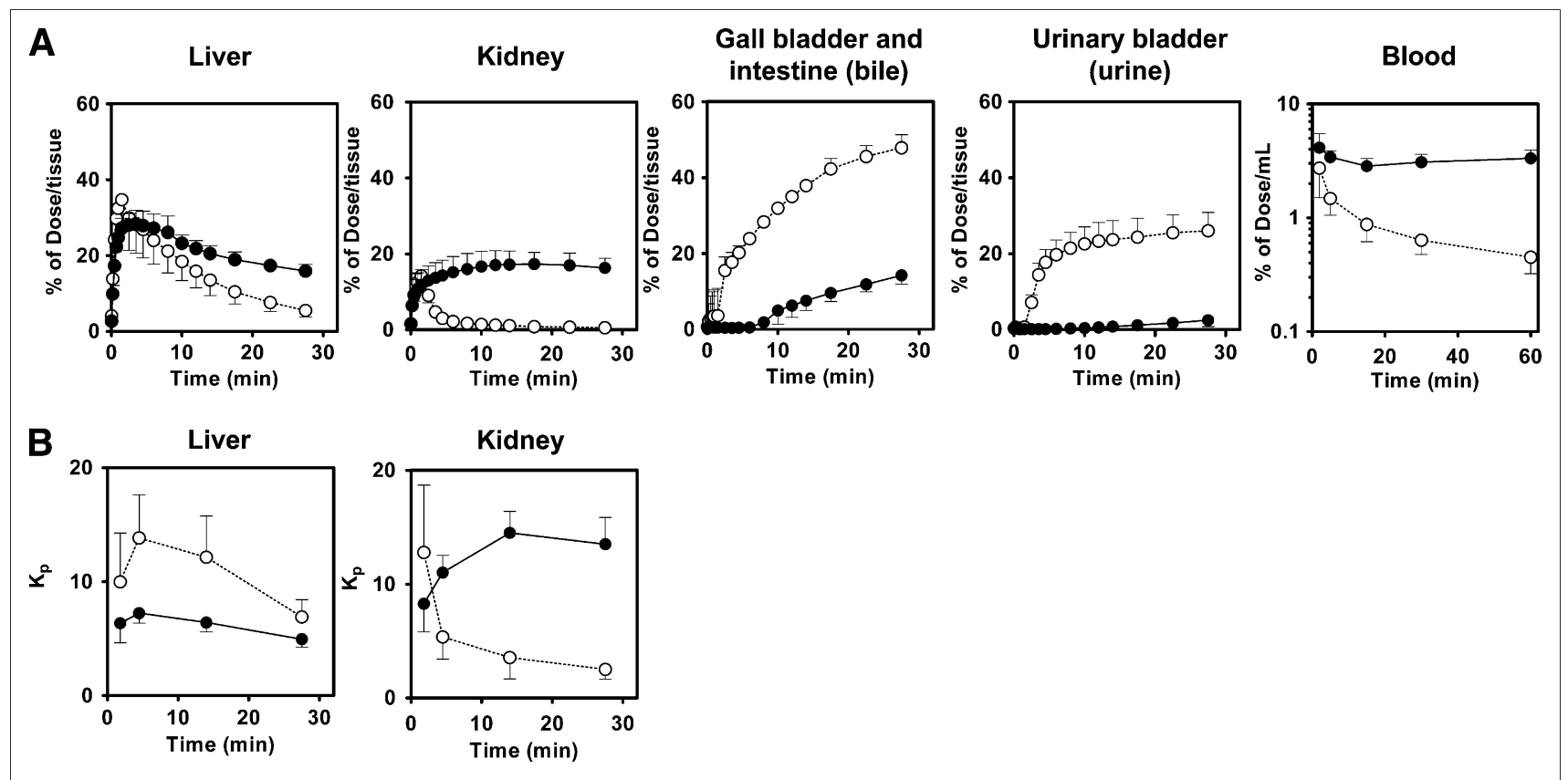

FIGURE 4. Radioactivity time profiles in tissue and blood after administration of ${ }^{11} \mathrm{C}-\mathrm{SC}-62807$ to wild-type and Bcrp ${ }^{-/-}$mice. (A) Radioactivity time profiles in liver, kidney, bile, urine, and blood of wild-type and $\mathrm{Bcrp}^{-/-}$mice determined using PET and blood sampling within 60 min of administration of ${ }^{11} \mathrm{C}$-SC-62807. (B) Time profiles of liver-to-blood and kidney-to-blood radioactivity ratios $\left(\mathrm{K}_{\mathrm{p}}\right)$ in wild-type and $\mathrm{Bcrp}^{-/-}$mice. Each symbol with bar represents mean $\pm \mathrm{SD}(n=4)$. Open and closed symbols represent wild-type and $B c r p^{-/-}$mice, respectively. 
TABLE 1

Pharmacokinetic Parameters of ${ }^{11} \mathrm{C}-\mathrm{SC}-62807$ in Wild-Type and Bcrp ${ }^{-1-}$ Mice

\begin{tabular}{|c|c|c|c|}
\hline Pharmacokinetic parameter & Wild-type mice & Bcrp ${ }^{-1-}$ mice & Ratio of $\mathrm{Bcrp}^{-/-}$to wild-type \\
\hline AUC $_{\text {blood,0-30 } \min }(\%$ dose $\times \min / \mathrm{mL})$ & $42 \pm 18$ & $93 \pm 19^{\star}$ & $2.2 \pm 1.1$ \\
\hline $\mathrm{AUC}_{\text {liver }, 0-30 \mathrm{~min}}(\%$ dose $\times \min / \mathrm{mL})$ & $369 \pm 85$ & $535 \pm 76^{\dagger}$ & $1.5 \pm 0.4$ \\
\hline $\mathrm{AUC}_{\text {kidney }, 0-30 \min }(\%$ dose $\times \mathrm{min} / \mathrm{mL})$ & $170 \pm 36$ & $1,119 \pm 126^{\ddagger}$ & $6.6 \pm 1.6$ \\
\hline $\mathrm{K}_{\mathrm{p}, \text { liver,Auc }(\mathrm{mL} / \mathrm{g} \text { of liver) }}$ & $8.8 \pm 3.0$ & $5.6 \pm 0.8$ & $0.64 \pm 0.24$ \\
\hline $\mathrm{K}_{\mathrm{p}, \mathrm{kidney}, \mathrm{AUc}}(\mathrm{mL} / \mathrm{g}$ of kidney) & $4.0 \pm 1.3$ & $11.7 \pm 2.3^{\star}$ & $2.9 \pm 1.1$ \\
\hline$X_{\text {bile,0-30 min }}(\%$ dose $)$ & $48 \pm 3$ & $13 \pm 2^{\ddagger}$ & $0.28 \pm 0.04$ \\
\hline $\mathrm{X}_{\text {urine,0-30 min }}(\%$ dose $)$ & $26 \pm 5$ & $3.0 \pm 1.7^{\ddagger}$ & $0.11 \pm 0.07$ \\
\hline $\mathrm{CL}_{\text {bile,blood,0-30 min }}(\mathrm{mL} / \mathrm{min} / \mathrm{kg})$ & $48 \pm 19$ & $5.1 \pm 1.6^{\dagger}$ & $0.11 \pm 0.05$ \\
\hline $\mathrm{CL}_{\text {renal,blood,0-30 min }}(\mathrm{mL} / \mathrm{min} / \mathrm{kg})$ & $25 \pm 8$ & $1.2 \pm 0.7^{\star}$ & $0.046 \pm 0.033$ \\
\hline $\mathrm{CL}_{\text {int, bile,liver }}(\mathrm{mL} / \mathrm{min} / \mathrm{kg})$ & $4.5 \pm 0.8$ & $1.2 \pm 0.1^{*}$ & $0.26 \pm 0.05$ \\
\hline $\mathrm{CL}_{\text {int,urine,kidney }}(\mathrm{mL} / \mathrm{min} / \mathrm{kg})$ & $13 \pm 2$ & $0.12 \pm 0.07^{\star}$ & $0.0088 \pm 0.0051$ \\
\hline \multicolumn{4}{|c|}{$\begin{array}{l}\text { *Unpaired } t \text { test, } P<0.01 \\
\text { †Unpaired } t \text { test, } P<0.05 \text {. } \\
\text { †Unpaired } t \text { test, } P<0.001 \text {. } \\
\text { Each value represents mean } \pm \text { SD }(n=3-4) \text {. Statistically significant difference was observed for several pharmacokinetic parameters } \\
\text { Bcrp }{ }^{-1-} \text { mice, compared with wild-type. }\end{array}$} \\
\hline
\end{tabular}

in $\mathrm{CL}_{\text {bile,blood,0-30 min }}$, whereas the difference in $\mathrm{CL}_{\text {int,urine, }}$ kidney between wild-type and $\mathrm{Bcrp}^{-/}$mice was much larger than the difference in $\mathrm{CL}_{\text {renal,blood,0-30 } \mathrm{min}}$.

\section{Estimation of SC-62807 Uptake Clearance and Contribution of OATP1B1 and OATP1B3 in Human Hepatocytes}

Uptake of SC-62807 by OATP1B1- and OATP1B3expressing cells and vector-transfected HEK293 cells (control) is shown in Figure 7. Uptake of SC-62807 was significantly higher in OATP-expressing cells than in control cells and was saturable, with $K_{\mathrm{m}}$ and $V_{\max }$ values of $260 \pm 138 \mu \mathrm{M}$ and $319 \pm 133 \mathrm{pmol} / \mathrm{min} / \mathrm{mg}$ of protein, respectively, for OATP1B1 and $19.8 \pm 2.56 \mu \mathrm{M}$ and $205 \pm$ $16.2 \mathrm{pmol} / \mathrm{min} / \mathrm{mg}$ of protein, respectively, for OATP1B3. The uptake clearance of SC-62807 mediated by OATP1B1 and OATP1B3 in human hepatocytes was estimated by comparing the uptake clearance of reference compounds $\left({ }^{3} \mathrm{H}-\mathrm{E}_{1} \mathrm{~S}\right.$ and $\left.{ }^{3} \mathrm{H}-\mathrm{CCK}-8\right)$ in transfectants and hepatocytes (Table 2). Clearance of SC-62807 mediated by OATP1B1

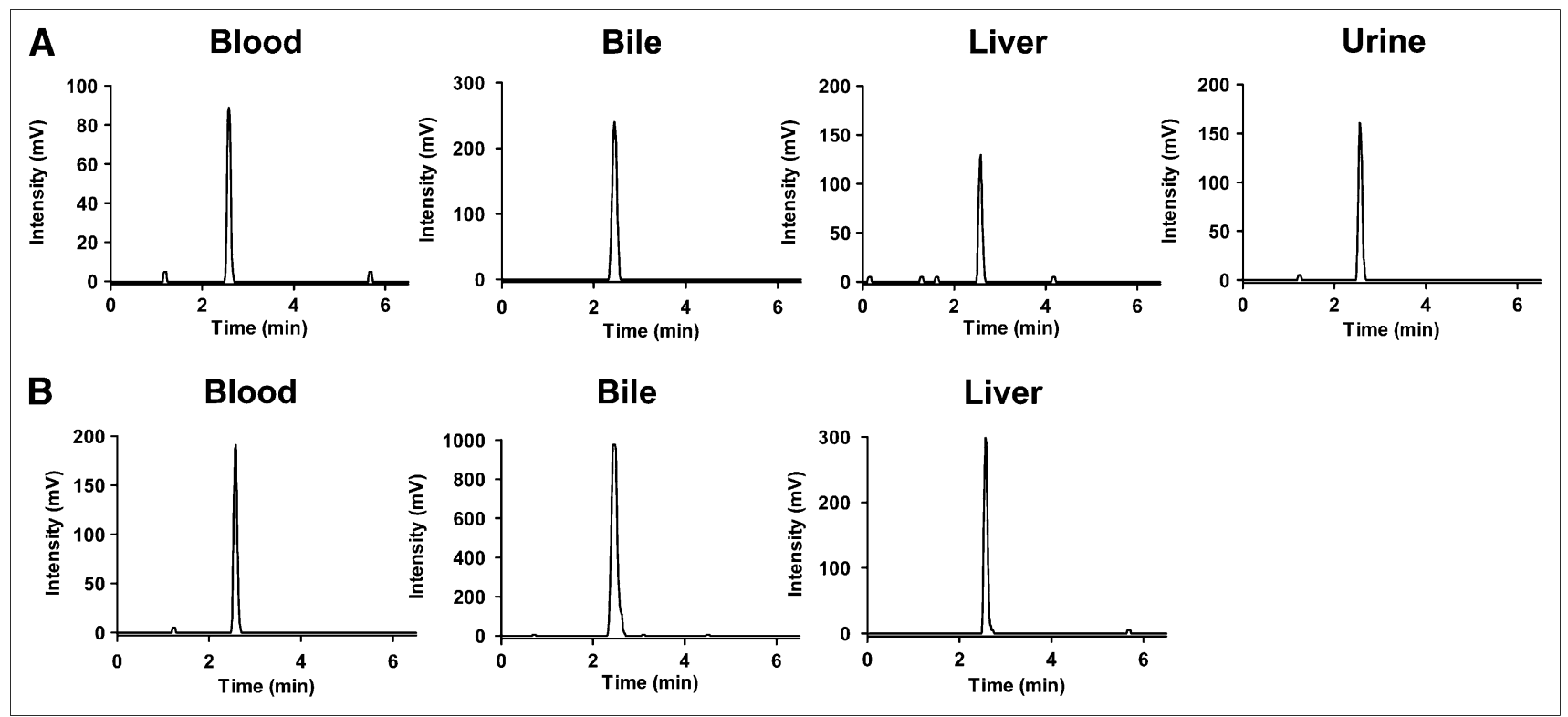

FIGURE 5. Representative high-performance liquid chromatograms of blood, bile, liver, and urine extracts from wild-type and Bcrp ${ }^{-/-}$ mice after administration of ${ }^{11} \mathrm{C}-\mathrm{SC}-62807$. (A) Radiochromatograms of blood extracts sampled at 15 min, bile extracts sampled from gallbladder at $30 \mathrm{~min}$, liver extracts sampled at $15 \mathrm{~min}$, and urine extracts sampled $15 \mathrm{~min}$ after administration of ${ }^{11} \mathrm{C}-\mathrm{SC}$-62807 to wild-type mice. (B) Radiochromatograms of blood extracts sampled at $15 \mathrm{~min}$, bile extracts sampled from gallbladder at 30 min, and liver extracts sampled 15 min after administration of ${ }^{11} \mathrm{C}-\mathrm{SC}-62807$ to $\mathrm{Bcrp}^{-/-}$mice. Radioactivity in urine of $\mathrm{Bcrp}{ }^{-/-}$mice was below detection limit for radiometric high-performance liquid chromatography. 


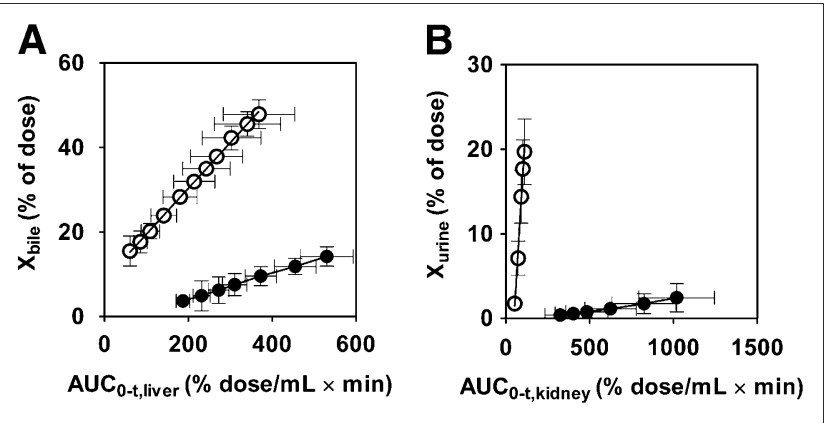

FIGURE 6. Integration plots for determination of canalicular efflux and renal secretion of total radioactivity in wild-type and $\mathrm{Bcrp}-/-$ mice. Integration plots were drawn for calculation of canalicular (A) and kidney brush-border (B) efflux of ${ }^{11} \mathrm{C}-\mathrm{SC}-62807$ in wild-type and $\mathrm{Bcrp}^{-1-}$ mice. Each symbol with bar represents mean $\pm \mathrm{SD}$ $(n=4)$. Open and closed symbols represent wild-type and Bcrp ${ }^{-/-}$ mice, respectively.

and OATP1B3 was similar in human hepatocytes as determined by $\mathrm{R}$ values (Table 2 ).

\section{DISCUSSION}

BCRP is an ATP-binding cassette transporter involved in biliary and renal excretion. The purpose of this study was to clarify the utility of ${ }^{11} \mathrm{C}-\mathrm{SC}-62807$ as a PET probe for analyzing the function of Bcrp in biliary and renal excretion in experimental animals and to demonstrate the feasibility of using ${ }^{11} \mathrm{C}-\mathrm{SC}-62807$ to assess BCRP function in humans. PET studies with ${ }^{11} \mathrm{C}-\mathrm{SC}-62807$ were designed to examine the kinetics of hepatobiliary transport and renal excretion in mice.
In vitro transport studies using mBcrp- and hBCRPexpressing membrane vesicles showed that SC-62807 is a substrate for BCRP in both mice and humans. This finding prompted us to investigate the tissue distribution and significance of Bcrp in the elimination of SC-62807 from the systemic circulation because Bcrp is normally expressed in the canalicular membrane of hepatocytes and the brushborder membrane on the proximal tubules in rodents $(I)$ as well as in the BBB and blood-placenta barrier.

PET revealed that ${ }^{11} \mathrm{C}-\mathrm{SC}-62807$ is excreted into the bile and urine. Because radiometabolite analyses indicated that radioactivity associated with ${ }^{11} \mathrm{C}-\mathrm{SC}-62807$ metabolites is negligible in the blood, liver, bile, and urine of mice, the total radioactivity represents the unchanged form. After intravenous bolus injection, ${ }^{11} \mathrm{C}-\mathrm{SC}-62807$ is predominantly excreted into the bile and, to a slightly lesser extent, into the urine. About $74 \%$ of the radioactivity was recovered in the bile and urine of wild-type mice within $30 \mathrm{~min}$ of administration. The ${ }^{11} \mathrm{C}-\mathrm{SC}-62807 \mathrm{CL}_{\text {renal,blood,0-30 min }}$ was greater than the reported creatinine clearance value $(8.7 \pm 2.0 \mathrm{~mL} / \mathrm{min} / \mathrm{kg})$ (30), indicating that tubular secretion contributes significantly to renal excretion.

Because BCRP is expressed in the apical membrane, its transport activity is tightly associated with the intrinsic efflux activity across the canalicular and brush-border membranes $\left(\mathrm{CL}_{\text {int,bile,liver }}\right.$ and $\left.\mathrm{CL}_{\text {int, urine,kidney }}\right)$. An advantage of PET is that it enables noninvasive monitoring of the tissue concentration to determine these parameters. Our PET analysis demonstrated that both biliary and renal excretion of ${ }^{11} \mathrm{C}-\mathrm{SC}-62807$ is significantly reduced in $\mathrm{Bcrp}^{-/}$mice, leading to prolonged systemic exposure to ${ }^{11} \mathrm{C}-\mathrm{SC}-62807$. The marked decrease in both $\mathrm{CL}_{\text {int,bile,liver }}$ and $\mathrm{CL}_{\text {int, urine,kidney }}$ in

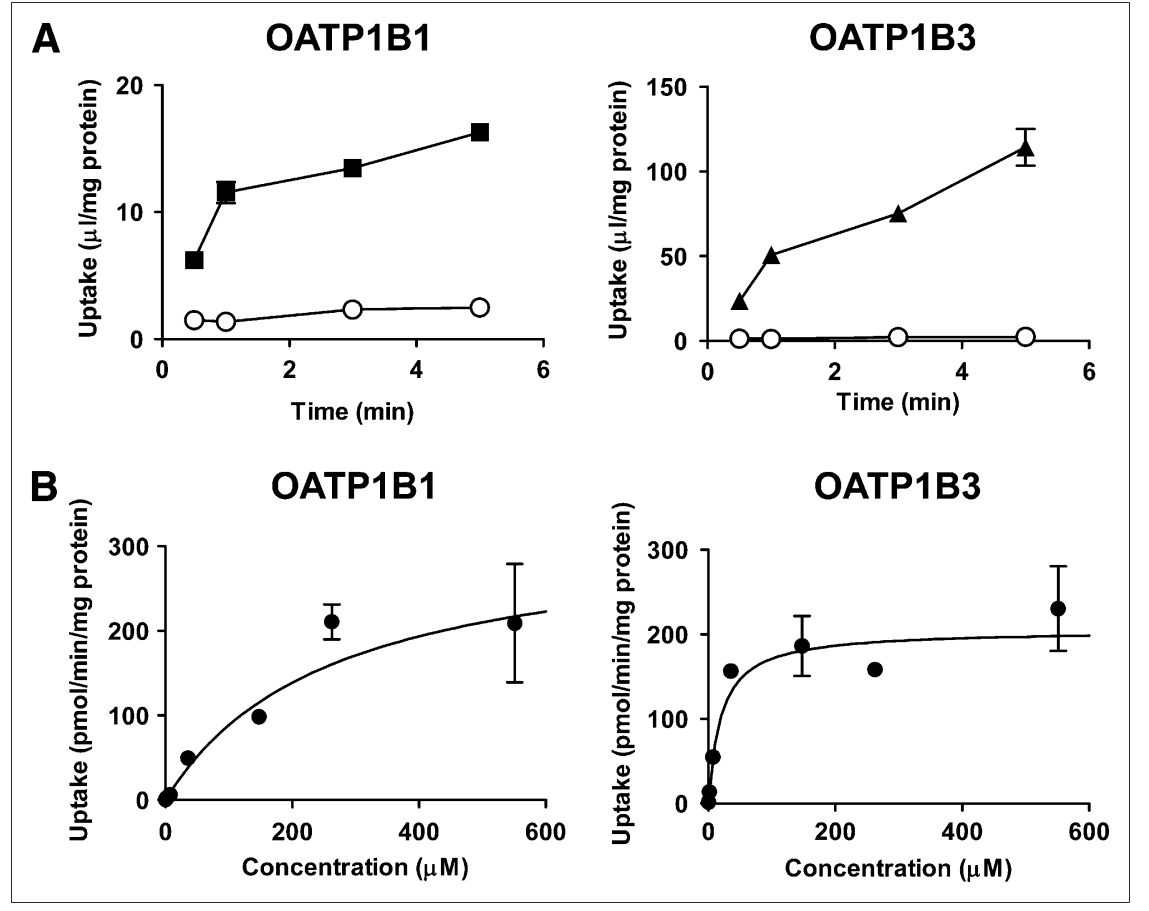

FIGURE 7. Time profiles of SC-62807 uptake by OATP1B1- and OATP1B3-expressing HEK293 cells and dependence of uptake on concentration. (A) Uptake of SC-62807 by human OATP1B1- (घ) and OATP1B3 ( $\Delta$ )-expressing HEK293 and mock cells $(O)$ was determined at $37^{\circ} \mathrm{C}$ at designated time. (B) Uptake of SC-62807 into OATP1B1- and OATP1B3-expressing HEK293 cells was determined with varying concentrations of $\mathrm{SC}-62807$ at $37^{\circ} \mathrm{C}$ for $1.5 \mathrm{~min}$. OATP1B1and OATP1B3-mediated transport was calculated by subtracting uptake in vectortransfected control cells from that in transporter-expressing cells. Data were fitted to Michaelis-Menten equation using nonlinear least-squares method, and each solid line represents fitted curve. Each point represents mean \pm SE $(n=3)$. 


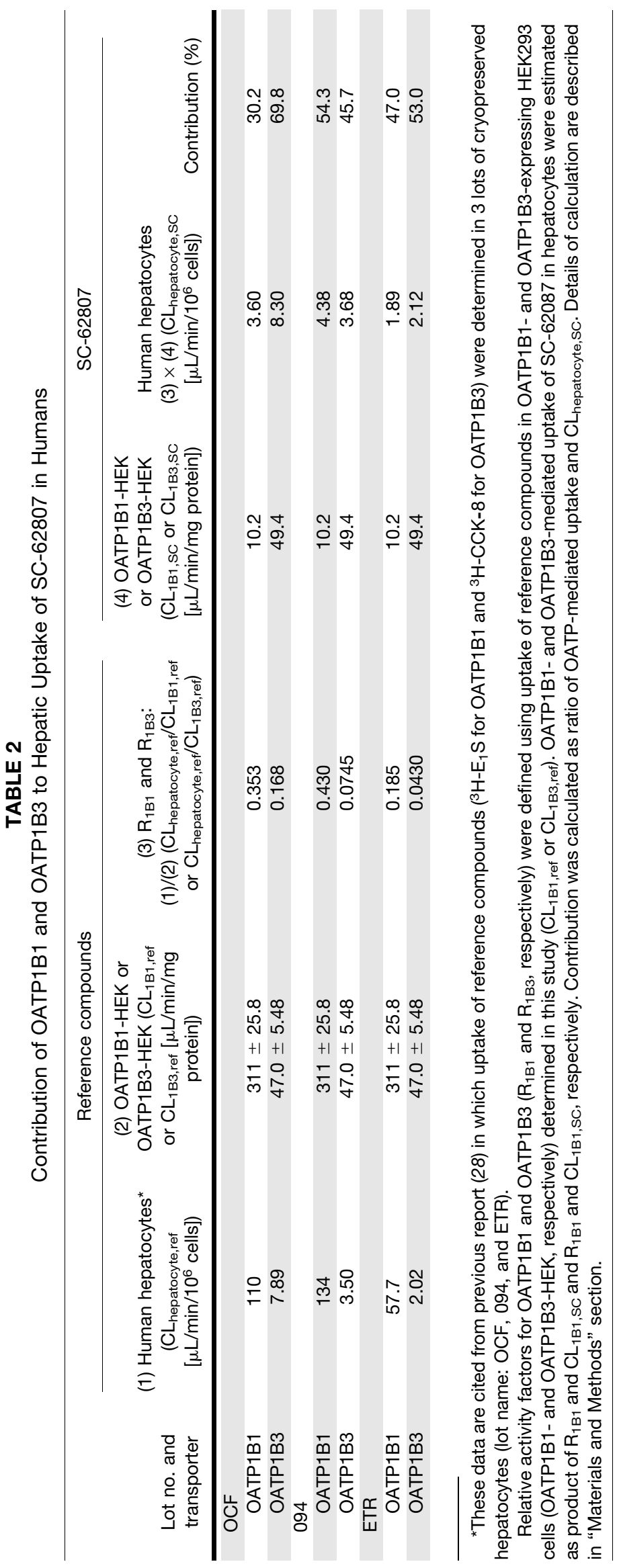


$B c r p^{-/}$mice clearly indicates that the predominant contribution of Bcrp to efflux of ${ }^{11} \mathrm{C}-\mathrm{SC}-62807$ into the bile and urine. The transporter Mrp2 is indispensable to the efflux of most anionic drugs into the bile. SC-62807 was also shown to be an in vitro substrate for Mrp2 using an uptake study involving MRP2-expressing membrane vesicles. However, the $\mathrm{V}_{\max } / \mathrm{K}_{\mathrm{m}}(5.6 \pm 1.5 \mu \mathrm{L} / \mathrm{min} / \mathrm{mg}$ of protein) was much lower than that for BCRP-expressing vesicles $(218 \pm$ $41 \mu \mathrm{L} / \mathrm{min} / \mathrm{mg}$ of protein). There was only a slight decrease in the radioactivity excreted into the bile in Mrp2-deficient rats, compared with normal rats (data not shown). These results confirmed the specificity of SC-62807 for Bcrp in canalicular efflux.

Consistent with the marked reduction in efflux into the urine, the ${ }^{11} \mathrm{C}-\mathrm{SC}-62807 \mathrm{~K}_{\mathrm{p}, \text { kidney }}$ was significantly higher in $\mathrm{Bcrp}^{-/}$mice than in wild-type mice. Despite the marked

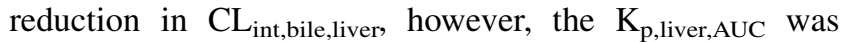
lower in $\mathrm{Bcrp}^{-/-}$mice, possibly due either to a low contribution of canalicular efflux to the net efflux from hepatocytes or to adaptive regulation caused by a Bcrp defect. The transporter Mrp3 is expressed on the sinusoidal membrane of hepatocytes, where it mediates the sinusoidal efflux of anionic drugs and glucuronide conjugates into the blood. Sinusoidal efflux mediated by Mrp3 may contribute significantly to net hepatocytic efflux, thereby attenuating the impact of Bcrp defects on the liver-to-plasma ratio. A reduction in influx mediated by an unknown mechanism or elevation in sinusoidal efflux may also explain the discrepancy, although there are no reports concerning adaptive regulation in the expression of drug transporters in the liver of $\mathrm{Bcrp}^{-/}$mice. We found that SC-62807 is a good in vitro substrate of OATP1B1 and OATP1B3 (Table 2). It is quite possible that rodent isoforms can mediate hepatic uptake of SC-62807. Further investigation is necessary to elucidate the mechanism underlying the discrepancy.

We also conducted ${ }^{11} \mathrm{C}-\mathrm{SC}-62807$ PET of mouse brain regions to demonstrate the utility of the technique for examining Bcrp function at the BBB. Brain penetration of ${ }^{11} \mathrm{C}-\mathrm{SC}-62807$ was low in both wild-type and $\mathrm{Bcrp}^{-/-}$mice, with the apparent tissue-to-blood concentration ratio $\left(\mathrm{K}_{\mathrm{p}}\right)$ values around 0.03 (Supplemental Fig. 1; supplemental materials are available online only at http://jnm.snmjournals.org). Generally, anionic drugs have low distribution volumes in the brain, presumably because of high protein binding in the plasma and low membrane permeability of the BBB. Thus, we concluded that the use of this probe for examining Bcrp function at the BBB may be impractical because of the likelihood of poor transport across the BBB.

PET enables the direct noninvasive measurement of intrinsic efflux across the canalicular and brush-border membranes. Using PET, we detected a marked reduction in canalicular and brush-border efflux of the radioactivity associated with ${ }^{11} \mathrm{C}-\mathrm{SC}-62807$ in $\mathrm{Bcrp}{ }^{-/-}$mice, demonstrating the feasibility of clinical investigations of BCRP variation using ${ }^{11} \mathrm{C}-\mathrm{SC}-62807$ as a radiotracer. It was reported that SC-62807, which is produced by oxidation of the antiinflammatory drug celecoxib, is found predominantly in the feces and urine after oral celecoxib administration in humans and that the amount of the glucuronide conjugate metabolite is low in both feces and urine (31), suggesting that ${ }^{11} \mathrm{C}$-SC-62807 should be minimally metabolized in humans when administered as an intravenous injection. The fact that SC-62807 is a good substrate of OATP1B1 and OATP1B3 in vitro suggests that SC-62807 is efficiently taken up by the liver from the blood circulation. In humans, SC-62807 is most likely excreted into the bile by transporters. These characteristics fulfill the conditions required for in vivo PET. Clinical studies with ${ }^{11} \mathrm{C}$ SC-62807 could elucidate the importance of BCRP in the disposition of drugs in humans and help resolve questions over interindividual differences in BCRP activity in the liver caused by genetic polymorphisms and sex differences.

\section{CONCLUSION}

We demonstrated the utility of noninvasive PET using ${ }^{11} \mathrm{C}-\mathrm{SC}-62807$ as a radiotracer for the functional characterization of Bcrp, a protein responsible for biliary and renal excretion. We also showed the feasibility of using this technique to assess BCRP-associated membrane transport in hepatobiliary and renal excretion in humans.

\section{DISCLOSURE}

The costs of publication of this article were defrayed in part by the payment of page charges. Therefore, and solely to indicate this fact, this article is hereby marked "advertisement" in accordance with 18 USC section 1734. This work was supported by a Grant-in-Aid for Young Scientists (B) (KAKENHI 21790171) from the Ministry of Education, Culture, Sports, Science and Technology (MEXT), Japanese government. This work was also supported by a Grant-in-Aid for Scientific Research on Innovative Areas HD-Physiology (23136101) from the Ministry of Education, Science, and Culture of Japan. No potential conflict of interest relevant to this article was reported.

\section{ACKNOWLEDGMENTS}

We are indebted to Emi Hayashinaka, Tomotaka Shingaki, and Kiyoshi Kyono of the RIKEN Center for Molecular Imaging Science; Masahiro Kurahashi of Sumitomo Heavy Industry Accelerator Service Ltd.; and Miyuu Yokochi and Sumito Ito of the Graduate School of Pharmaceutical Sciences, The University of Tokyo, for their expert technical support.

\section{REFERENCES}

1. Jonker JW, Buitelaar M, Wagenaar E, et al. The breast cancer resistance protein protects against a major chlorophyll-derived dietary phototoxin and protoporphyria. Proc Natl Acad Sci USA. 2002;99:15649-15654.

2. Schinkel AH, Mol CA, Wagenaar E, van Deemter L, Smit JJ, Borst P. Multidrug resistance and the role of P-glycoprotein knockout mice. Eur J Cancer. 1995;31A:1295-1298.

3. Cascorbi I. Role of pharmacogenetics of ATP-binding cassette transporters in the pharmacokinetics of drugs. Pharmacol Ther. 2006;112:457-473. 
4. Doyle LA, Ross DD. Multidrug resistance mediated by the breast cancer resistance protein BCRP (ABCG2). Oncogene. 2003;22:7340-7358.

5. Allen JD, Schinkel AH. Multidrug resistance and pharmacological protection mediated by the breast cancer resistance protein (BCRP/ABCG2). Mol Cancer Ther. 2002;1:427-434.

6. Chu XY, Kato Y, Niinuma K, Sudo KI, Hakusui H, Sugiyama Y. Multispecific organic anion transporter is responsible for the biliary excretion of the camptothecin derivative irinotecan and its metabolites in rats. J Pharmacol Exp Ther. 1997;281:304-314.

7. van Herwaarden AE, Schinkel AH. The function of breast cancer resistance protein in epithelial barriers, stem cells and milk secretion of drugs and xenotoxins. Trends Pharmacol Sci. 2006;27:10-16.

8. Enokizono J, Kusuhara H, Ose A, Schinkel AH, Sugiyama Y. Quantitative investigation of the role of breast cancer resistance protein (Bcrp/Abcg2) in limiting brain and testis penetration of xenobiotic compounds. Drug Metab Dispos. 2008;36:995-1002.

9. Hirano M, Maeda K, Matsushima S, Nozaki Y, Kusuhara H, Sugiyama Y. Involvement of BCRP (ABCG2) in the biliary excretion of pitavastatin. Mol Pharmacol. 2005;68:800-807.

10. Mao Q, Unadkat JD. Role of the breast cancer resistance protein (ABCG2) in drug transport. AAPS J. 2005;7:E118-E133.

11. Breedveld P, Zelcer N, Pluim D, et al. Mechanism of the pharmacokinetic interaction between methotrexate and benzimidazoles: potential role for breast cancer resistance protein in clinical drug-drug interactions. Cancer Res. 2004;64:5804-5811.

12. Yamasaki Y, Ieiri I, Kusuhara H, et al. Pharmacogenetic characterization of sulfasalazine disposition based on NAT2 and ABCG2 (BCRP) gene polymorphisms in humans. Clin Pharmacol Ther. 2008;84:95-103.

13. Zhang W, Yu BN, He YJ, et al. Role of BCRP 421C $>$ A polymorphism on rosuvastatin pharmacokinetics in healthy Chinese males. Clin Chim Acta. 2006;373:99-103.

14. Matsuo H, Takada T, Ichida K, et al. Identification of ABCG2 dysfunction as a major factor contributing to gout. Nucleosides Nucleotides Nucleic Acids. 2011;30:1098-1104.

15. Pysz MA, Gambhir SS, Willmann JK. Molecular imaging: current status and emerging strategies. Clin Radiol. 2010;65:500-516.

16. Bergström M, Grahnen A, Langstrom B. Positron emission tomography microdosing: a new concept with application in tracer and early clinical drug development. Eur J Clin Pharmacol. 2003;59:357-366.

17. Willmann JK, van Bruggen N, Dinkelborg LM, Gambhir SS. Molecular imaging in drug development. Nat Rev Drug Discov. 2008;7:591-607.
18. Ghibellini G, Leslie EM, Pollack GM, Brouwer KL. Use of tc-99m mebrofenin as a clinical probe to assess altered hepatobiliary transport: integration of in vitro, pharmacokinetic modeling, and simulation studies. Pharm Res. 2008;25:1851-1860.

19. Takashima T, Nagata H, Nakae T, et al. Positron emission tomography studies using (15R)-16-m-[ $\left[{ }^{11} \mathrm{C}\right]$ tolyl-17,18,19,20-tetranorisocarbacyclin methyl ester for the evaluation of hepatobiliary transport. J Pharmacol Exp Ther. 2010;335:314-323.

20. Takashima T, Kitamura S, Wada Y, et al. PET imaging-based evaluation of hepatobiliary transport in humans with (15R)- ${ }^{11} \mathrm{C}-\mathrm{TIC}-\mathrm{Me} . \mathrm{J}$ Nucl Med. 2012;53: 741-748.

21. Kawamura K, Yamasaki T, Konno F, et al. Evaluation of limiting brain penetration related to P-glycoprotein and breast cancer resistance protein using $\left[{ }^{11} \mathrm{C}\right]$ GF120918 by PET in mice. Mol Imaging Biol. 2011;13:152-160.

22. Kawamura K, Yamasaki T, Yui J, et al. In vivo evaluation of P-glycoprotein and breast cancer resistance protein modulation in the brain using $\left[{ }^{11} \mathrm{C}\right]$ gefitinib. Nucl Med Biol. 2009;36:239-246.

23. Tang C, Shou M, Mei Q, Rushmore TH, Rodrigues AD. Major role of human liver microsomal cytochrome P450 2C9 (CYP2C9) in the oxidative metabolism of celecoxib, a novel cyclooxygenase-II inhibitor. J Pharmacol Exp Ther. 2000; 293:453-459.

24. Takashima-Hirano M, Takashima T, Katayama Y, et al. Efficient sequential synthesis of PET Probes of the COX-2 inhibitor $\left[{ }^{11} \mathrm{C}\right]$ celecoxib and its major metabolite $\left[{ }^{11} \mathrm{C}\right] \mathrm{SC}-62807$ and in vivo PET evaluation. Bioorg Med Chem. 2011; 19:2997-3004.

25. Guide for the Care and Use of Laboratory Animals. Bethesda, MD: National Institutes of Health; 1985. NIH publication 86-23.

26. Kondo C, Suzuki H, Itoda M, et al. Functional analysis of SNPs variants of BCRP/ABCG2. Pharm Res. 2004;21:1895-1903.

27. Hirouchi M, Suzuki H, Itoda M, et al. Characterization of the cellular localization, expression level, and function of SNP variants of MRP2/ABCC2. Pharm Res. 2004;21:742-748.

28. Yamaoka K, Tanigawara Y, Nakagawa T, Uno T. A pharmacokinetic analysis program (multi) for microcomputer. J Pharmacobiodyn. 1981;4:879-885.

29. Hirano M, Maeda K, Shitara Y, Sugiyama Y. Contribution of OATP2 (OATP1B1) and OATP8 (OATP1B3) to the hepatic uptake of pitavastatin in humans. J Pharmacol Exp Ther. 2004;311:139-146.

30. Mizuno N, Suzuki M, Kusuhara H, et al. Impaired renal excretion of 6-hydroxy-5, 7-dimethyl-2-methylamino-4-(3-pyridylmethyl) benzothiazole (E3040) sulfate in breast cancer resistance protein (BCRP1/ABCG2) knockout mice. Drug Metab Dispos. 2004;32:898-901.

31. Paulson SK, Hribar JD, Liu NW, et al. Metabolism and excretion of $\left[{ }^{14} \mathrm{C}\right]$ celecoxib in healthy male volunteers. Drug Metab Dispos. 2000;28:308-314. 